\title{
PROTÓTIPO DE JOGO PARA O ENSINO DE ANÁLISE E GESTÃO DE BACIAS HIDROGRÁFICAS
}

\author{
Cintia Dias Coelho $^{(\mathrm{a})}$, Ronaldo da Silva Monteiro ${ }^{(\mathrm{b})}$, Raul Reis Amorim ${ }^{(\mathrm{c})}$ \\ (a) Departamento de Geografia, Instituto de Geociências, Unicamp, cintiadiasferreira@gmail.com \\ (b) Departamento de Geografia, Instituto de Geociências, Unicamp, ronaldomonteiro@live.com \\ (c) Departamento de Geografia, Instituto de Geociências, Unicamp, raul_reis@ige.unicamp.br
}

\section{Eixo: GEOGRAFIA FÍSICA: CURRICULO, FORMAÇÃO E PRÁTICAS DE ENSINO}

\begin{abstract}
Resumo
O presente trabalho criou um protópito de um jogo para o ensino de análise e gestão de bacias hidrográficas. Este jogo de tabuleiro trata de aspectos relacionados a outorga e uso dos recursos hidricos nas doze regiões hidrográficas do território brasileiro, permitindo assim, uma visão ampla sobre as potencialidades e limitações de cada região. Aborda temáticas sobre uso e manejo de solo, análise das bacias, usos consuntivos e não consuntivos dos recursos hídricos e práticas de gestão de águas. A proposta de elaboração deste jogo está atrelada ao Programa de Estágio Supervisionado do curso de Geografia e ao Programa do Serviço de Apoio ao Estudante (SAE/UNICAMP), desenvolvidos no Instiuto de Geociências da Unicamp. O jogo é indicado para para estudantes de Ensino Médio e Graduação em áreas afins a temática proposta.
\end{abstract}

Palavras chave: Recursos hídricos, regiões hidrográficas, jogos.

\section{Introdução}

A água é um recurso indispensável a vida humana e está presente no nosso cotidiano desde o simples consumo ao seu incremento nas mais variadas atividades econômicas desenvolvidas ao redor do mundo, sabemos que a humanidade no decorrer de sua história praticou não só o nomadismo, mas, também o sedentarismo, essas constatações são vistas nos mais variados livros de história e geografia em que vemos que as populações humanas começaram a se fixar em determinados locais devido as disponibilidades de alimentos e hídricas, sendo que, um grande exemplo disso é o povo egípcio que se fixou nas margens do rio Nilo e ali desenvolveu a agricultura e consequentemente a irrigação e seu estilo de vida (TUNDISI e REBOUÇAS, 2006; CECH, 2013).

O conhecimento sobre os recursos hídricos foi de suma importância para a materialização dos primeiros assentamentos humanos e ainda hoje os recursos hídricos possuem importância em nossas sociedades, além disso é sabido que a água é um recurso finito e que por mais que o planeta Terra possua grandes reservas de água, as mesmas não estão 100\% disponíveis para captação, conforme Machado e Torres (2012). Os autores apontam que no Planeta Terra 68,7\% da água está armazenada em forma congelada, 


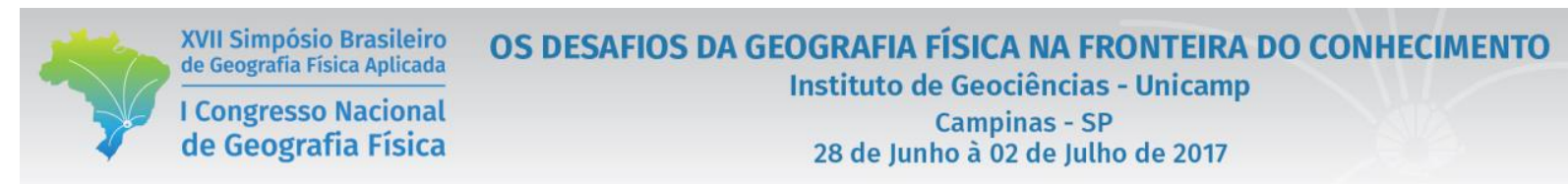

$30,1 \%$ de água doce no subsolo e 1,2\% em outras reservas. Cabe ressaltar que 97,47\% da água está em reservatórios com sais, e que somente $2,53 \%$ da água é doce. Com o crescimento das demandas de consumo para diferentes atividades é cada vez mais necessário a realização de debates em torno dessa temática, pois, vemos as mais variadas disputas ocasionadas pela água que se tornarão ainda mais críticas num futuro próximo.

A abordagem da temática dos recursos hídricos deve ser difundida em todos os níveis escolares, e uma possibilidade de abordar o tema é a partir do uso de materiais didáticos lúdicos como os jogos.

Verri e Endlich (2009) afirmam que a adoção de estratégias de ensino que adotam os jogos melhora a compreensão e a aprendizagem dos alunos de forma que a inclusão dos níveis de conhecimento que resultem em habilidade e atitudes na formação dos mesmos.

As autoras ainda destacam que:

O jogo vem como um estímulo tanto para melhor compreensão do conteúdo, quanto para o crescimento e o desenvolvimento intelectual do aluno é fundamental para atingir a responsabilidade e a maturidade. ... uma forma de aproximar o conteúdo aos alunos motivando-os a estudar de forma mais atrativa (VERRI e ENDLICH, 2009, p. 64).

Breda e Picanço (2013, p.5-6) tratam dos cuidados que deve-se ter no uso deste recurso didático:

Os jogos no ambiente de sala de aula devem ser desenvolvidos e trabalhados com cautela, de forma a contribuir para o processo de ensino aprendizagem da criança, principalmente quando visar trabalhar algum conteúdo escolar, ou quando dentro do ambiente da escola. Deve-se evitar, por exemplo, que a atividade possa se tornar um material que desperte uma competição negativa, ou que se constitua numa mera atividade recreativa. A competição durante o jogo precisa ser sadia e natural, em que o aluno não busque tão somente superar seus desafios, mas agregar conhecimentos a fim de obter o desenvolvimento das competências e habilidades da Geografia como a correlação e análise/localização

Tendo o exposto, o objetivo deste trabalho foi construir um jogo que possibilita tratar de questões emergentes no que tange a temática dos Recursos Hídricos no Brasil. O uso do jogo como um material didático tem o intuito de despertar o interesse dos estudantes desta temática para que os mesmos tenham conhecimento das questões ligadas aos recursos hídricos e um primeiro contato com as noções de análise e gestão dos mesmos.

\section{Metodologia}

Após a promulgação da Política Nacional de Recursos Hídricos (PNRH) o Brasil compartimentou o seu território em 12 regiões hidrográficas: Amazônica, Atlântico Leste, Atlântico Nordeste Ocidental, Atlântico Nordeste Oriental, Atlântico Sudeste, Atlântico Sul, Paraguai, Paraná, Parnaíba, São Francisco, 
Tocantins Araguaia e Uruguai. Cada uma das regiões hidrográficas possui características particulares que ditam a dinâmica hidrográfica da sua área de abrangência e que são de suma importância para a fixação dos assentamentos populacionais, para o desenvolvimento das atividades humanas que serão implantadas na região e para a análise e gestão dos recursos hídricos disponíveis.

Para entendermos sobre os processos e dinâmicas das diferentes regiões hidrográficas brasileiras inventariou-se os seus atributos físicos, sociais e econômicos de cada uma das regiões hidrográficas. Outros aspectos levantados referem-se a disponibilidade e demanda dos recursos hídricos, seu potencial e uso na navegação, geração de energia, principais problemas ambientais, além das questões ligadas a outorga da água. As principais fontes de dados foram os trabalhos publicados por Brasil (2005), Brasil (2007a), Brasil (2007b), Brasil (2007c), Brasil (2011) e Brasil (2015).

Após a finalização da pesquisa bibliográfica, iniciamos uma outra etapa do projeto, afim de buscar um meio para a produção do jogo. Para tal, utilizamos um layout tradicional de jogos de tabuleiro de estratégia. O layout do jogo foi desenvolvido e softwares estão sendo utilizados, o Corel DRAW 7 e o Adobe Photoshop. Estas ferramentas digitais possibilitam a criação de um conteúdo dinâmico e visualmente atrativo, despertando interesse e interação. Ao finalizarmos a produção digital do jogo, iniciaremos uma série de testes para analisar a sua viabilidade, detectando e corrigindo prováveis erros de planejamento que impeçam a sua jogabilidade.

\section{A construção do jogo}

A proposta de criação do jogo teve como motivação uma ferramenta de ensino e aprendizagem lúdica dos instrumentos de Gestão de Bacias Hidrográficas no território brasileiro. O jogo foi intitulado como "Água + Gestão".

A primeira etapa foi definir o formato do jogo: em múltiplas reuniões e discussões do grupo, definiu-se que o jogo teria um tabuleiro, e que teriam até seis jogadores simultâneos. Cada jogador seria um "usuário da água", que buscaria cumprir um objetivo no jogo: conseguir a outorga de bacias hidrográficas em duas regiões hidrográficas e implantar atividades de uso consuntivo e não consuntivo. Como exemplo, temos a carta objetivo representada pela Figura 1: 


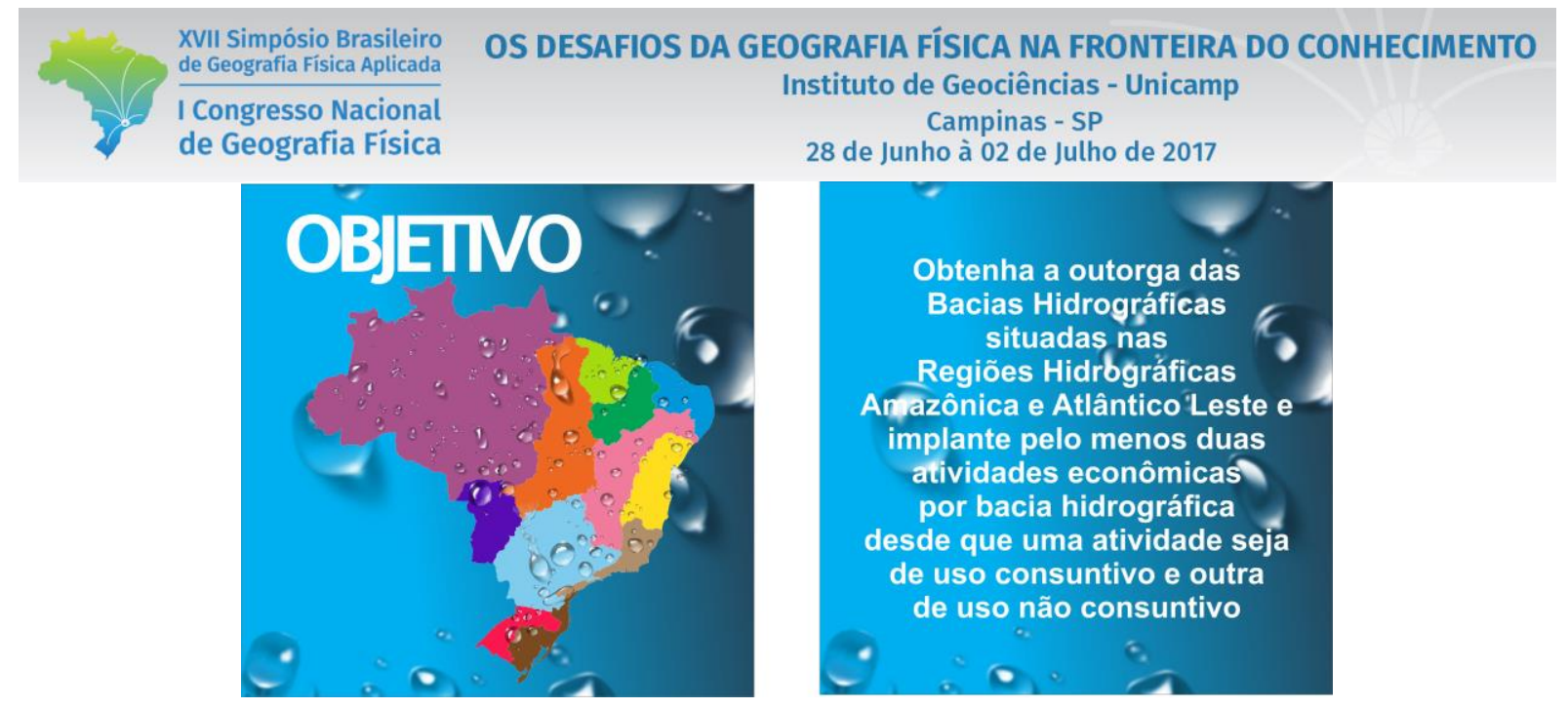

Figura 1 - Exemplo de Carta Objetivo do Jogo "Água + Gestão"

O jogo é composto por um conjunto cartas objetivo e do tabuleiro, o jogo é composto por um manual com regras, um dado, notas de dinheiro fictício utilizado para as ações que necessitam de compra, para o arrendamento temporário, outorgas, implementação de atividades de usos consuntivos ou não consuntivos, além do pagamento de multas relativas ao uso inadequado dos recursos hídricos. O jogo também tem cartas de ação denominadas como "Ações de Manejo", cartões que indicará, quais os tipos de uso consuntivos e não consuntivos cada Região Hidrográfica tem o potencial, e pequenas fichas-ícones que indicam os diferentes tipos de usos consuntivos e não consuntivos implantados nas bacias hidrográficas.

O tabuleiro é composto pela casa início, 10 casas que indicam ações de manejo, 3 casas que indicam a ocorrência de desastres e 29 casas que indicam diferentes bacias hidrográficas situadas nas diferentes regiões hidrográficas brasileiras.

A seleção das bacias hidrográficas baseou-se no inventário. Foram selecionadas 2 ou 3 bacias hidrográficas para representar cada região hidrográfica. Os critérios que basearam a escolha foram rios conhecidos que desenvolvem atividades econômicas significativas na sua respectiva Região Hidrográfica.

Também se pesquisou quais são os principais potenciais de uso dos recursos hídricos para cada Região Hidrográfica. Isso foi necessário, para que o jogador não implantasse uma atividade que a Bacia Hidrográfica não tenha o potencial. Por exemplo: dentre as atividades de uso não consuntivos está a navegação. Nas bacias hidrográficas situadas na Região Hidrográfica Nordeste Oriental e Nordeste Ocidental, este potencial é baixo, desta forma, na ficha que indica os principais tipos de usos consuntivos e não-consuntivos a serem implantados nestas bacias hidrográficas, a navegação não está incluída.

A Tabela 1 e a Figura 2 mostram as Bacias Hidrográficas selecionadas para compor o tabuleiro. 
Tabela 1 - Bacias Hidrográficas selecionadas por Região Hidrográfica para compor o tabuleiro do jogo "Agua + Gestão".

\begin{tabular}{|c|c|c|c|}
\hline Região Hidrográfica & Bacias Hidrográficas & Região Hidrográfica & Bacias Hidrográficas \\
\hline RH Amazonica & $\begin{array}{ll}- & \text { BH do Rio Madeira } \\
\text { - } & \text { BH do Rio Negro } \\
\text { - } & \text { BH do Rio Tapajós } \\
\end{array}$ & RH Paraná & $\begin{array}{ll}\text { - } & \text { BH Rio Tietê } \\
\text { - } & \text { BH Rio Paraná } \\
\text { - } & \text { BH Rio Grande } \\
\end{array}$ \\
\hline RH Tocantins-Araguaia & $\begin{array}{ll}\text { - } & \text { BH do Rio Tocantins } \\
\text { - } & \text { BH do Rio das Mortes } \\
\text { - } & \text { BH do Rio Araguaia } \\
\end{array}$ & RH Uruguai & $\begin{array}{ll}\text { - } & \text { BH Uruguai } \\
\text { - } & \text { BH Rio do Peixe } \\
\text { - } & \text { BH Chapecó } \\
\end{array}$ \\
\hline RH São Francisco & $\begin{array}{ll}\text { - } & \text { BH Rio Grande } \\
\text { - } & \text { BH Rio São Francisco } \\
\text { - } & \text { BH Rio das Velhas } \\
\end{array}$ & BH Paraguai & $\begin{array}{ll}\text { - } & \text { BH Paraguai } \\
\text { - } & \text { BH Taquari } \\
\text { - } & \text { BH São Lourenço } \\
\end{array}$ \\
\hline RH Nordeste Oriental & $\begin{array}{l}\text { - BH Capibaribe } \\
\text { - } \text { BH Paraíba } \\
\end{array}$ & RH Atlântico Leste & $\begin{array}{l}\text { - } \text { BH Jequitinhonha } \\
\text { - } \text { BH Pardo }\end{array}$ \\
\hline RH Nordeste Ocidental & $\begin{array}{l}\text { - } \text { BH Mearim } \\
\text { - } \quad \text { BH Itapecuru } \\
\end{array}$ & RH Atlântico Sudeste & $\begin{array}{l}\text { - BH Paraíba do Sul } \\
\text { - BH Doce }\end{array}$ \\
\hline RH Parnaíba & $\begin{array}{l}\text { - BH Parnaíba } \\
\text { - BH Canindé }\end{array}$ & RH Atlântico Sul & $\begin{array}{ll}\text { - } & \text { BH Capivari } \\
\text { - } & \text { BH Itajaí } \\
\end{array}$ \\
\hline
\end{tabular}




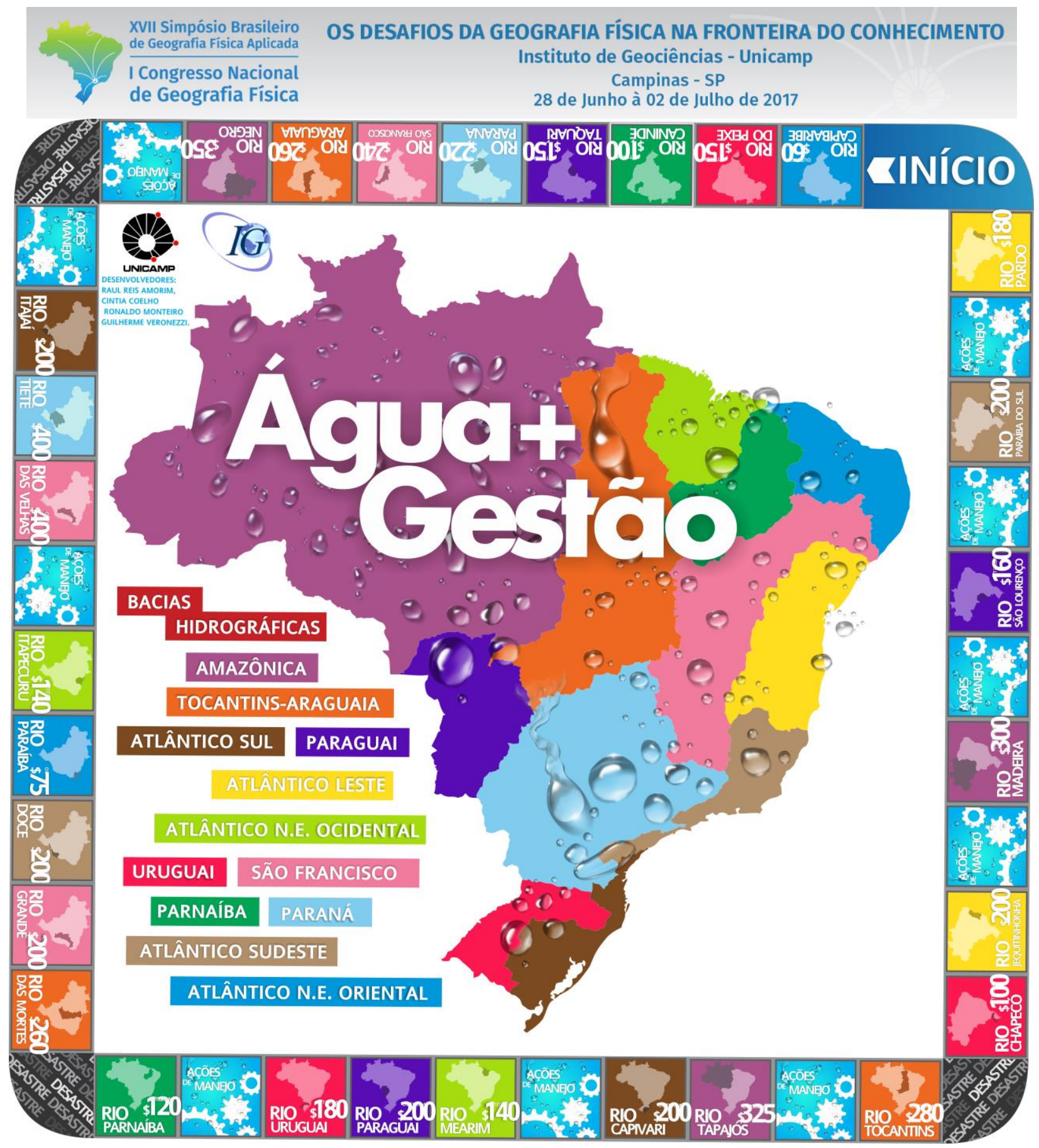

Figura 2 - Visualização prévia do layout do tabuleiro em desenvolvimento.

As cartas de Ações de Manejo irão simular atividades realizadas dentro das bacias hidrográficas, respeitando as suas características de viabilidade para implantação de ações de manejo em cada bacia de acordo com os conceitos de uso consuntivo e não consuntivo das águas. Elas serão divididas entre ações de manejo adequado, que darão saldo positivo, e também as de ação de manejo inadequado, que resultarão em multa, conforme o exemplo da Figura 3. 


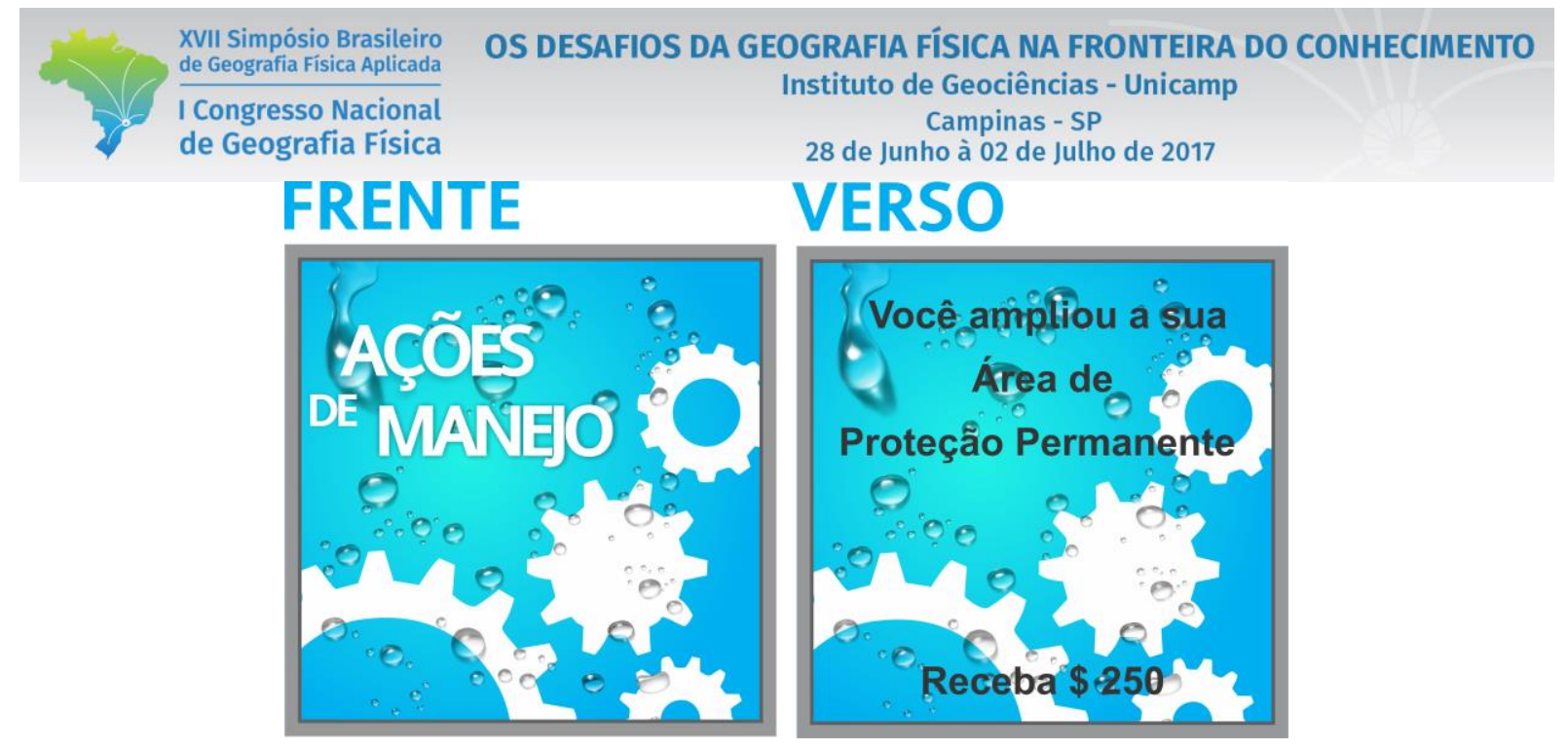

Figura 3 - Carta de Ações, exemplificando uma ação de manejo adequado:

\section{Regras do Jogo}

As cartas de objetivo serão distribuídas no início do jogo, e sua função será determinar quais serão as bacias hidrográficas que os jogadores terão que adquirir a propriedade, afim de obter o direito de outorga, para implantar as atividades de usos consuntivos e não consuntivos. Nesse cenário, vence o jogo quem cumprir os objetivos previamente estipulados no início, através da carta de objetivo ou o único jogador que conseguir estabelecer estratégias de boa gestão das suas bacias até o final do jogo, de acordo com todas as regras previamente estipuladas. Nada impede que os jogadores adquiram bacias hidrográficas em outras regiões hidrográficas que não atendam a seu objetivo.

Para início do jogo, cada um dos jogadores receberá uma quantia em notas de dinheiro fictício, para que possam adquirir o direito de outorga das bacias hidrográficas. Serão distribuídas 20 notas de \$ 5, 20 notas de \$ 10, 10 notas de \$20,10 notas de \$ 50 e 5 notas de \$100. Cada jogador iniciará o jogo com \$1500. As notas são ilustradas na Figura 4.

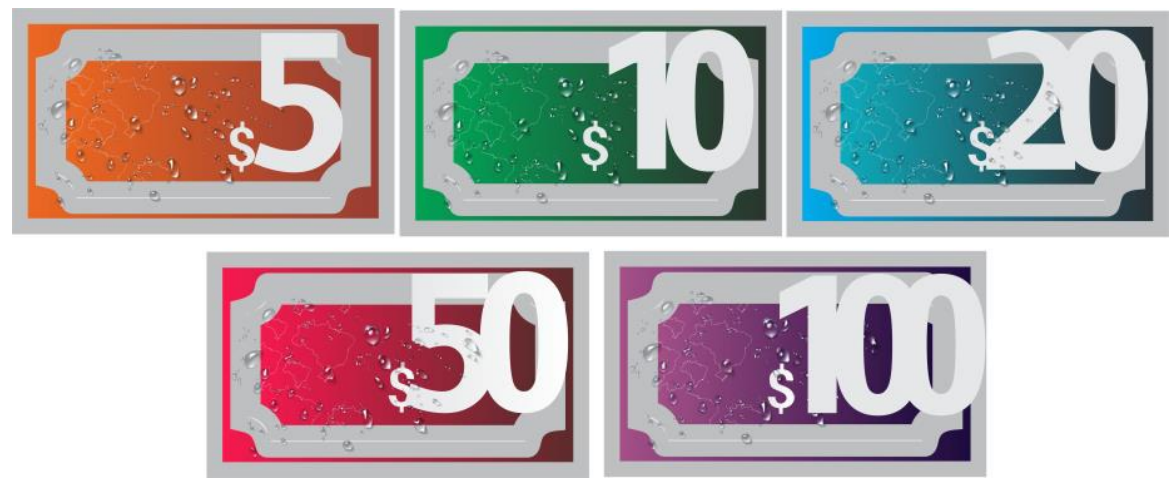

Figura 4 - Representação das moedas utilizadas no jogo. 
Posteriormente, cada jogador irá lançar seu dado. O primeiro a jogar será o jogador que tirar o número maior. A ordem de jogo seguirá o sentido horário. O primeiro jogador também será o responsável por gerenciar a Agência de Águas (órgão responsável por conceder a outorga da água, autorizar a implantação de atividades econômicas e uso da terra nas bacias hidrográficas).

O primeiro jogador lançará seu dado. O pino andará o número de casas indicadas pelo dado. Ao cair numa casa, o jogador terá as seguintes possibilidades:

- Ao cair em uma Bacia Hidrográfica que ainda não tem outorga, o mesmo pode solicita-la a Agência de Águas. No tabuleiro, o valor de solicitação de outorga está indicado para cada Bacia Hidrográfica. O jogador irá receber da Agência de Águas um título de outorga da respectiva bacia.

- Se o jogador tiver o direito de outorga da bacia hidrográfica ele pode consultar nas cartas de tipo de uso e ocupação das bacias hidrográficas quais os tipos de uso consuntivos e não consuntivos podem ser implantados nesta região hidrográfica. Se decidir implantar uma atividade econômica, o jogador deve pagar para a Agência de Águas a taxa correspondente para aquele tipo de uso.

- Se a bacia hidrográfica já tiver outorgada para outro jogador, o mesmo deverá pagar uma taxa de uso da infraestrutura (arrendamento) da bacia ao seu outorgante. Por exemplo, temos o espaço destinado ao rio Uruguai que terá como valor do terreno: $\mathrm{R} \$ 180$, arrendamento: $\mathrm{R} \$ 14$, uma atividade não consuntiva: $\mathrm{R} \$ 70$, duas atividades não consuntivas: $\mathrm{R} \$ 200$, uma atividade consuntiva: $\mathrm{R} \$ 550$, duas atividades consuntivas: $\mathrm{R} \$ 750$, duas atividades consuntivas e duas não consuntivas: R\$ 950. As informações de cobrança pelo arrendamento estão na carta que dá direito a outorga da Bacia Hidrográfica

Além das casas de bacias hidrográficas, o jogador encontrará no tabuleiro casas com espaços para atuar com ações de manejo adequado ou a ocorrência de desastres.

No caso das ações de manejo, toda vez que o jogador cair em uma das 10 casas que indiquem essa ação, ele deve retirar uma carta. Estas irão simular atividades realizadas dentro das bacias hidrográficas, respeitando as suas características de viabilidade para implantação de ações de manejo em cada bacia de acordo com os conceitos de uso consuntivo e não consuntivo das águas. Cada carta pode indicar uma ação de manejo positiva ou negativa. O jogo tem 15 cartas de ações de manejo positivas e 15 cartas de ações de manejo negativas. 
No caso do jogador que cair na casa "desastre", este terá que indicar uma das suas bacias hidrográficas a ser atingida por esta adversidade. Todos os tipos de uso consuntivos e não consuntivos implantados da bacia hidrográfica serão destruídos, desta forma, os ícones que representam tais ações serão retirados e devolvidos a Agência de Águas.

\section{Considerações Finais}

A proposta de criação do protótipo de um jogo voltado ao ensino de Geografia, dando ênfase aos estudos de Análise e Gestão de Bacias Hidrográficas se mostrou bastante estimulante, principalmente para os alunos do curso de graduação em Geografia que desenvolveram o projeto durante um ano de estágio no Programa do Serviço de Apoio ao Estudante -SAE/UNICAMP, através da Bolsa Auxílio Social (BAS).

O jogo foi proposto para alunos do Ensino Médio e para alunos do Ensino Superior que tratem da temática relacionada a Análise e Gestão de Bacias Hidrográficas. As habilidades e competências exigidas para este jogo, necessitam de um conhecimento mais amplo da Política Nacional de Recursos Hídricos.

Este projeto realizou a primeira etapa: a construção do jogo. As próximas etapas serão: aplicação do jogo em turmas da disciplina Estágio Supervisionado em Geografia I e II, obtenção de sugestões e críticas para o ajuste da proposta final do jogo.

\section{Bibliografia}

Agência Nacional de Águas (Brasil). O Comitê de Bacia Hidrográfica: o que é e o que faz? / Agência Nacional de Águas. -- Brasília: SAG, 2011.

BRASIL. Conjuntura dos recursos hídricos no Brasil: regiões hidrográficas brasileiras - Edição Especial. -- Brasília: ANA, 2015.

BRASIL. Ministério do Meio-Ambiente. Agência Nacional de Águas (ANA). Cadernos de recursos hídricos 1: Panorama da qualidade das águas superficiais no Brasil. Superintendência de Planejamento de Recursos Hídricos - Agência Nacional de Águas (ANA). - Brasília: TDA Desenho \& Arte Ltda , 2005. 
BRASIL. Ministério do Meio-Ambiente. Agência Nacional de Águas (ANA). Cadernos de recursos hídricos 2: Disponibilidade e demandas de recursos hídricos no Brasil. Superintendência de Planejamento de Recursos Hídricos - Agência Nacional de Águas (ANA). - Brasília: TDA Desenho \& Arte Ltda , 2007a.

BRASIL. Ministério do Meio-Ambiente. Agência Nacional de Águas (ANA). Cadernos de recursos hídricos 3: A Navegação Interior e sua Interface com o Setor de Recursos Hídricos no Brasil e Aproveitamento do Potencial Hidráulico para Geração de Energia no Brasil. Agência Nacional de Águas (ANA). - Brasília: TDA Desenho \& Arte Ltda , 2007b.

BRASIL. Ministério do Meio-Ambiente. Agência Nacional de Águas (ANA). Cadernos de recursos hídricos 4: Diagnóstico da outorga de direito de uso de recursos hídricos no Brasil, e, Fiscalização dos usos de recursos hídricos no Brasil Agência Nacional de Águas (ANA). - Brasília: TDA Desenho \& Arte Ltda , 2007c.

BREDA, Thiara; PICANÇO, Jefferson. O uso de jogos no processo de ensino-aprendizagem na geografia escolar. Encontro de Geógrafos da America Latina, v. 14, p. 1-19, 2013.

CECH, Thomas V. Recursos hídricos: história, desenvolvimento, política e gestão. Rio de Janeiro: LTC, 2013.

OLIVEIRA, P. J.; TORRES, F. T. P. Introdução à hidrogeografia. São Paulo: Cengage Learning, 2012.

TUNDISI, J. Galizia; BRAGA, Benedito; REBOUÇAS, Aldo C. Águas doces no Brasil. 2006.

VERRI, Juliana Bertolino; ENDLICH, Angela. A utilização de jogos aplicados no ensino de Geografia. Revista Percurso, v. 1, n. 1, p. 65-83, 2009. Geografia. Revista Percurso, v. 1, n. 1, p. 65-83. 2009 